\title{
La herencia imposible
}

\author{
Beatriz Blanco VÁzQuEZ \\ UNED \\ escrituraeimagen@filos.ucm.es
}

\section{Resumen}

A partir de una lectura cruzada entre la novela 2666 de Roberto Bolaño y el libro Glas de Jacques Derrida, esta ponencia intenta esbozar las condiciones de la herencia y del trabajo de duelo a partir de sus bordes internos, los restos y el archivo. Para ello efectúa un recorrido cartográfico por la dificultosa recepción de Glas, oscilando indedidiblemente entre la biodegradabilidad y la resistencia inasimilable. Esa cartografía imposible de un libro, que es también el resto inasimilable del que hace tema, deja inscribir el texto como espacio de duelo y otra figura del duelo más allá del trabajo.

Palabras clave: resto, biodegradabilidad, duelo, archivo, escritura.

\begin{abstract}
Based on a combined reading of Roberto Bolaño's novel 2666 and Derrida's Glas, this paper aims at sketching the conditions of inheritance and the work of mourning from their inner edges, the remains and the archive. For this purpose, this paper sets out on a cartographic journey across the difficult reception of Glas, oscillating undecidibly between biodegradability and inassimilable resistance. This impossible cartography of a book, which is also the inassimilable remainder of which it makes the theme, allows for inscribing the text as a space of mourning, and as another figure of mourning beyond the work.
\end{abstract}

Key words: Remain(der), biodegradability, mourning, archive, writing. 
"Entre las piedras volcánicas había bolsas de mercado llenas de basura. Recordó que su hijo, que estudiaba en Phoenix, una vez le había contado que las bolsas de plástico tardaban cientos, tal vez miles de años en consumirse . Estas de aquí no, pensó al ver el grado de descomposición a lo que todo estaba abocado. En lo alto unos niños salieron corriendo y se perdieron cerro abajo, rumbo a la colonia Estrella". ${ }^{1}$

Las bolsas de basura llenan el cerro. Ni naturaleza ni ciudad, el vertedero -lugar de acumulación de los restos -oculta el lugar del crimen, tornándose en cementerio imposible. No hay lugar del crimen -insiste un joven policía en la novela de Bolaño -tampoco hay lugar para sepulturas o cortejos fúnebres allí donde la repetición de las muertes reincide en lo interminable de cualquier duelo, donde tantas muertas innominadas terminan en fosas comunes. Hace falta un nombre para el duelo. La novela de Bolaño trata de hacer una historia del dolor irrepresentable de las mujeres que aún mueren en Ciudad Juárez. Dicha novela, con vocación de clásico y la fragilidad de lo póstumo, erra quizá; pero deja vislumbrar su pretensión de ser a la vez duelo y lugar de las muertes. No se puede hacer un cementerio entre las basuras del cerro, hace falta establecer los lugares, rememorar los nombres; el libro se erige, entonces, en cementerio suplementario.

Esa breve descripción narra la visita del inspector al lugar donde apareció la última mujer asesinada. Las bolsas sobre los cerros recuerdan a un tiempo que no es ni el de la vida, ni el de la muerte, a un tiempo que no es tampoco la eternidad como presente pleno: el tiempo de lo no-del-todo biodegradable, del resto y del desecho del consumo como producción. El inspector, incapaz de resolver los crímenes, rechaza la resistencia o la restancia de las bolsas de plástico: el viento del desierto destruye todos los restos, los residuos y aquello que los contiene, al igual que borra las huellas que dejan los cuerpos de las mujeres asesinadas. La duración indeterminable de los restos incómoda al inspector; es evidente. El plástico no es biodegradable, sí el libro. A no ser que el libro se haga metonimia del vertedero, que pese a todos los intentos de catalogar los restos falle, dejándolos caer, pero recogiendo la trayectoria de su caída en un clamor inaudible.

Enterrar los restos, permitir que sean rememorados, asignarles un nombre y un lugar -la (im)posibilidad del duelo - es la condición de la herencia. Entre el cementerio y el vertedero se traza el espacio del libro, y, en él, la posibilidad de aceptarlo como herencia. ¿Crearán las bolsas de los cerros una nueva naturaleza que se confunda con la ya existente? ¿Pasará un texto a alimentar o a introducirse en el campo del saber establecido perdiendo incluso su condición singular? Qué mejor y qué peor. Lo biodegradable está en un doble vínculo: perderse para ganarse y rentabilizarse. No se hereda lo completamente biodegradable, algo tiene que restar para que

1 Bolaño, Roberto: 2666 (Barcelona, Anagrama, 2004); p. 452. 
haya herencia, pero tampoco todo resto es heredable. El otro lado de la herencia es el residuo que va a ocupar los vertederos, cuya duración pone en riesgo la vida. Sin embargo, en cualquier legado está presente el rechazo. Entre la asimilación o incorporación y la exclusión o supresión se mueve cualquier trabajo de duelo: doble movimiento indecidible que nunca se cierra ni se detiene, que excluye la clausura del que lo realiza. Y cabe señalar que todo trabajo es en cierto modo trabajo de duelo: introyección/deyección de un resto espectral, suspensión del tiempo del resto. Toda herencia es imposible aunque haya que responder de ella, pero que algo pueda ser heredado requiere de la institución, de la familia, de la ley como performativo que se impone desde otro tiempo al que hereda. No todo es heredable, pero tampoco cualquiera puede heredar. El trabajo de duelo hace nacer la legitimidad, funda la familia; trabaja los restos para que no desaparezcan del todo, los introyecta para contenerlos, les pone nombre para no devorarlos; pero nunca concluye, si es que llega a iniciarse. Para re-iniciar el trabajo del duelo, hay que reconocer los restos como propios. ¿Cómo llega, pues, a hacerse propio un resto?

Dejemos cuerpos y bolsas pudrirse en los vertederos. En la frontera más grande del mundo el tiempo de la aniquilación se ha acelerado. Hecho esto, es posible que las miasmas infecten la ciudad, abandonar los restos hace correr el riesgo de la contaminación. Quizá nos envenenen. No hay quien se libre de los residuos y no se puede evitar producirlos al producir, son el doble espectral de cualquier trabajo. Esto Derrida lo ha dicho ya, en un libro que se mantiene en el borde indeterminable de intentar hacer tema del resto. El libro sobre el resto (si así se deja nombrar) se habría tornado un resto - cuyo trabajo de duelo tal vez no se haya iniciado -en una torsión que se asemeja mucho a un bucle reflexivo. Antes de decíroslo he empezado por hablar de Glas.

¿Qué queda de Glas? Como si me hubiese leído antes de mi nacimiento, retorcido tiempo del libro, aquel anticipa la pregunta y disemina las respuestas, como si se hubiese leído a sí mismo. Ese "sí mismo" sólo llega a ser inscribible por un proceso de duelo. Más allá de su cuerpo textual, de lo escrito sobre él, Glas (esa pieza radicalmente idiosincrática en la filosofía contemporánea) es también lo no-escrito en él, los lugares donde no ha intervenido: el espacio en blanco entre las columnas (caja de resonancia), la superficie en apariencia indemne del mar -el propio Derrida lo dijo ya en 19772 .

¿Qué nos queda, entonces? Quizá, el libro, pero ese artículo determinante esconde la pluralidad irreductible de los libros y de cada libro. Además, que algo quede no quiere decir que haya herencia ¿Podríamos heredar las bolsas de basura

\footnotetext{
2 Derrida, Jacques : « Ja ou le faux-bond» en Points de suspensions (Paris, Galilée, 1992); p. 42 y ss. Esta es la segunda parte, publicada en la revista Digraphe en 1977, de una entrevista realizada por Denis Kambouchner en la que Derrida es preguntado por el mecanismo de construcción de Glas y la recepción de la obra hasta esa fecha.
} 
del cerro? ¿Querríamos hacerlo? La pregunta es ridícula. El rechazo del resto, su condición de fuera de la ley, no se deja domesticar en la figura familiar de la herencia; pero los residuos permanecen, impropios y nos contaminan, en grado tanto mayor cuanto menos queramos hacernos cargo. El trabajo sobre los restos de restos ha incidido en lo inacabable del duelo, un duelo que no es el suyo, o el propio (aunque también lo sea), un duelo de otros, re-citado y re-iterado, parasitario. El libro se habría elaborado como cripta impropia abriendo una historia de no-recepción, de inefectividad. Vínculo indecidible de la recepción de una obra: por una parte, Glas no ha dejado huella, se ha borrado, ha resultado ser completamente biodegradable. En ese caso habría pasado a alimentar el campo de la cultura actual sin ser reconocible. Por la otra, Glas permanece como resto no asimilable. La escasez de publicaciones al respecto y lo tardío de su traducción (aunque la situación ha ido cambiando en los últimos años ${ }^{3}$ ) lo revelan: herencia pendiente de reclamación por la necesidad de hacer duelo del duelo. En ambos casos, lo que queda es un residuo potencialmente peligroso que quizá ya haya iniciado un proceso de contaminación imperceptible de la que tal vez aún haya un "árido cerro testigo".

En este punto, querría -yo también - contar una historia, ficticia como cualquier otra, de la génesis de un libro y su recepción, del proceso de reinscripción constante de cada lectura efectuada o rechazada, tratando de estirar el retorcido tiempo del libro en una narración, en la que puede caber hasta un sentido, o incluso ciertas tesis.

\section{Historia de una no-recepción}

Quedémonos con una fecha, con un nombre: 1974, publicación de Glas. Alrededor de esa época salen al mercado cultural otros textos que tendrán una historia bastante diferente a la del libro que tratamos, El Antiedipo se editaba en 1972, en 1973 El placer del texto, en 1975 el seminario Encore de Lacan, en $1977 \mathrm{Mil}$ mesetas. En todos ellos se estaba produciendo un desplazamiento del campo conceptual de la década anterior. En cierto modo, elaboraban su duelo. Si comparamos la suerte de los libros de Deleuze y Guattari con la de Glas, los resultados son reveladores. En ambos se lleva a cabo una confrontación con cierto psicoanálisis y con

\footnotetext{
${ }^{3}$ La primera traducción de Glas es americana y data de 1986. La llevó a cabo J. Leavy junto a un equipo de colaboradores y se editó en dos volúmenes, al texto en inglés lo acompañaban las referencias hurtadas de Glas, un glosario de términos y una serie de artículos, que más que un estudio crítico de la obra jugaban a remedar su estilo. Hasta el 2006 no encontramos más traducciones del libro. En ese año se publican la traducción italiana a cargo de Silvano Facioni (en una colección de clásicos filosóficos dirigida por G. Reale) y la alemana de Hans-Dieter Gondek y Markus Sedlaczek. En estos momentos un grupo de investigación que dirige Cristina de Peretti está ultimando la traducción española.
} 
cierto marxismo, pero el gesto que cada uno amaga para hacerlo es por completo diferente e igualmente su repercusión. Los libros de Deleuze y Guattari son introducidos de inmediato en el campo cultural, citados y re-citados, traducidos con mayor o menor éxito a otros dominios. Su relevancia política es indiscutida y sigue produciendo efectos. A primera vista, la historia de Glas es exactamente la opuesta. Había algo en esos pedazos de escritura cerrados en forma de libro que lo hacía indigerible, inasimilable, ya no digamos heredable. Quizá, un trabajo con la lengua radicalmente idiosincrático, un ensañamiento con el soporte y con sus límites, una exposición violenta (aunque suene paradójico) de la vulnerabilidad del firmante. Había algo en Glas que se resistía, que hacía imposibles las digestiones precipitadas. Y, sin embargo, no es menos cierto que, en el momento de su publicación, fue objeto de numerosas reseñas en la prensa cultural que lo celebraban como el primer libro de Jacques Derrida e insistían en su originalidad y la radicalidad de su operación 4 . También se publicaron algunos artículos sobre él en una línea muy telqueliana, restos de la avant-garde que no tuvieron continuidad ni en la obra de su autor 5 . A esa pequeña explosión le sigue un silencio casi total sobre el texto. Los artículos sobre Glas son escasos, ni media docena en el ámbito literario, análisis en algunas introducciones al pensamiento de Derrida o la deconstrucción, referencias fragmentarias en libros sobre Genet, normalmente para contraponerlo a la magna obra de Sartre6. El campo hegeliano francés no lo consideró digno de mención y en una obra editada a principios del 2000 por Labarrière ni siquiera se incluye en la bibliografía sobre Hegel en Francia, en Alemania apenas nombrar a dos expertos foráneos Gabriella Baptist y J.M. Ripalda7. Fueron los estudios literarios anglosajones los

\footnotetext{
4 Anquetil, Gilles: "Glas, le nouveau livre de J. Derrida", Nouvelles Littéraires 2457 (28.10. 1974). Pachet, Pierre: "Une entreprise troublante", Quinzaine Littéraire 197 (01.11. 1974), 19-20. Merlin, Frédéric: "Pour qui sonne glas", Nouvelles Littéraires 2461 (25.11. 1974), 10. Blanchard, Gérard: "A propos de Glas", Communication et Langages 26 (1974), n.p. Loriot, P.: "Glas, par J. Derrida", Nouvel Observateur 256 (09.12. 1974), n.p. Delacampagne, Christian: "Hegel et Gabrielle, le 'premier' livre de Jacques Derrida", Monde des livres 9321 (03.01. 1975), 12. Parenti, Claire: "Glas", Magazine Littéraire 96:1 (1975), 38. E incluso la prensa italiana se hizo eco de la publicación: Agosto, Stefano: "Glas, libro scandaloso. Per chi suona questa campana", Il Giorno, 15.01.1975Wood, Michael: "Deconstructing Derrida", New York Review of Books 3. March 1977, 27-30.

5 Es el caso de François Laruelle, por ejemplo : Laruelle, François: "Le style di-phallique de Jacques Derrida", Critique 334 (mars 1975), 320-339

6 Podemos destacar los dos artículos dedicados a Glas por Jane Marie Todd Todd (Jane-Marie: "Autobiography and the Case of the Signature: Reading Derrida's Glas", Comparative Literature 38:1 (1986), Todd, Jane-Marie:”The Philosopher as Transvestite: Textual Revision in Glas.” Marshall, Donald G. (ed.). Literature as Philosophy/Philosophy as Literature. Iowa City: U of Iowa P, 1987) y en lo que respecta a Sartre el trabajo de Christina Howells (Howells, Christina M.: "Derrida and Sartre: Hegel's Death Knell”, Hugh Silverman, ed., Derrida and Deconstruction. New York: Routledge 1989).

7 Baptist, Gabriella, and Lucas, H.C.: "Wem schlägt die Stunde in Derridas Glas." Hegel-Studien, vol. 23 (1988). Baptist, Gabriella: "La scrittura falsa. Glas e La Carte Postale di Jacques Derrida",
} 
que se hicieron cargo marginalmente del libro, que parecía no decir demasiado a la filosofía institucionalizada. Ni siquiera una compilación de artículos bajo el titulo Hegel after Derrida ha tenido la trascendencia esperada. En Francia, incluso los primeros trabajos de Catherine Malabou ${ }^{8}$ parecen restaurar o domesticar la ruptura radical en el corpus de Hegel que supuso Glas. Un punto y aparte sería Jean Luc Nancy pero él ha proseguido su propia lectura de Hegel, iniciada con anterioridad a Glas y de la que Glas se hace eco en cierto modo, divergiendo del anti-hegelianismo ambiente9.

Es como si hubiese algo en Glas que se resiste cuando tratamos de escribir sobre él; el libro incomoda. Tomemos, más como síntoma que como ejemplo, dos lecturas que tuvieron lugar a finales de los 70 entre conocedores de la obra de Derrida: el libro es o bien monumentarizado como obra modernista 10 o bien rechazado por monumentarizante, reduciéndolo a su vez a una escena paterno-filial, una reescritura del origen, que si bien deja su huella en Glas no agota el libro'11. Las resistencias a Glas de la mano de sus intérpretes se repiten, nunca sabemos donde cortar, siempre se cita demasiado y demasiado largo, se parafrasea sin saber muy bien donde empieza Hegel o Genet ni donde Derrida, que es comentario, que meta-comentario, que motivos se toman y que motivos se introducen, como injertos animales o vegetales en un cuerpo humano. El libro produce restos que resisten. Como las bolsas de plástico no es biodegradable, o quizá sí y el inspector tenga razón: incluso las bolsas terminarán por desaparecer con el aire del desierto.

¿Es Glas un residuo persistente, inasimilable o un monumento indescifrable, resto venerable pero resto? ¿O tal vez se haya biodegradado hasta tal punto que no haya dejado ni rastro de su desaparición, humus que alimenta el revival hegeliano

Intersezioni 19:2 (1989) y "Jacques Derrida per 1'amicizia de Hegel: a proposito de Glas".

"Einige Vorbermerkungen zur französischen Hegelrezeption em XX. Jahrhundert J. M. Ripalda, Hegel ou le pré-texte...Des-cendres de Hegel y Hegel ou le pré-texte...Pour-parler(s) de Derrida de Cristina de Peretti" en Hegel und die Geschichte der Philosophie (vol. 2) Hegel-Jahrbuch, Akademie Verlag, 1998.

Ripalda J. M" Introducción a la Filosofía Real" en Hegel, G.W.F. Filosofía Real (edición y traducción de J. M. Ripalda) Madrid, F.C.E., 2006; y Ripalda, J. M. "Huellas de Hegel", Éndoxa Series Filosóficas, n 12, Madrid, Uned, 2000.

8 Por ejemplo en la reelaboración que realiza de su tesis doctoral para un libro colectivo sobre la actualidad de Hegel: Malabou, Catherine. "L'avenir de Hegel ou de la plasticité temporelle en dialectique" en Verstraeten, P. Hegel aujourd'hui, Paris, Vrin, 1995.

9 Antes de Glas, Nancy había publicado La Remarque spéculative (Nancy, J.L: La remarque spéculative, Paris, Galilée, 1973) y continuará su trabajo sobre Hegel en libros posteriores así Hegel y la inquietud de lo negativo (Nancy, J.L: Hegel y la inquietud de lo negativo, Madrid, Arena, 2005). En cuanto a Glas, podemos encontrar referencias en un libro reciente de Nancy (J. L: Tumba de sueño, Buenos Aires, Amorrortu, 2008).

10 Es el caso de Hartmann (Hartman, Geoffrey: "Monsieur Texte: On Jacques Derrida. His Glas." Georgia Review 29.4, 1975).

11 Cf. Spivak, Gayatri: “Glas-pieces: A compte rendu” Diacritics, Fall 7:3, 1977. 
en el presente? De algún modo siempre quedan restos, si Glas no ha podido inscribirse en lo simbólico, habrá tenido efectos que retornen como lo real. El residuo no asimilado, ni siquiera introyectado, ignorado en el afuera del tiempo del monumento, quizá haya contaminado al campo filosófico que no lo recibió. Esto habría sucedido sin que nos diésemos cuenta. Busquemos huellas: la insistencia de Zîzek en la función de un resto contingente, él mismo no reflexionable, en la reflexión hegeliana; la re-lectura de la Antígona por Judith Butler ${ }^{12}$, por citar a dos teóricos que no esconden sus deudas con Hegel, un poco más las que tienen con Derrida. Arriesguemos una hipótesis, los restos de un Glas en descomposición han alimentado el retorno hegeliano en este cambio de siglo, pero sólo lo habrán hecho a costa de no reconocerlo como herencia, de tratar de eliminar por una operación de reciclaje, siempre un tanto apresurada, un residuo contaminante. Éste, pese a ello, no pudo eliminarse del todo, en algún momento empezó a causar efectos. Uno de estos efectos, sigamos con nuestra historia, podría ser la lectura de Glas que lleva a cabo Fredric Jameson (durante tanto tiempo no interesado en Derrida) en su último libro Valences of dialectics ${ }^{13}$. En esta época que califica de "revival hegeliano" y de la que afirma que ha llegado el momento de replantearla de modo crítico, ya ni siquiera los herederos del marxismo pueden pasar de Glas. Pero en esa vuelta a Hegel, demasiado apremiante, ya nadie parecía interesarse por la pregunta que abre Glas: quoi du reste ici maintenant pour nous d'un Hegel? Ni por la que le sigue qui, lui? ${ }^{14}$ Hay que limpiar los restos rápido, concluir con los problemas legales en torno a la herencia y dar por sentado que el muerto está muerto y es utilizable. ¿Quién es el muerto en este caso? ¿Hegel? ¿Y qué denota ese nombre propio?¿Un cuerpo o un corpus textual, cómo delimitar donde empieza y donde acaba ese corpus? ¿No es acaso Hegel también las interpretaciones que han venido a incrustarse sobre un corpus aún no delimitado ni expurgado de elementos ajenos? Al menos una columna de Glas podría pertenecer a ese corpus, pero como miembro protético que no viene a suplir una falta sino a introducir un exceso. La lectura de Jameson insiste en las perplejidades (la principal: es Hegel el que parece estar deconstruyéndose anticipándose a la lectura de Derrida), perplejidades que tienen algo de denegación. De nuevo, el libro genera resistencias. Como ya habría señalado, en la sesión de Confrontations a la que Derrida fue invitado, René Major: nuestro cuerpo no sale indemne del cuerpo a cuerpo con la escritura que lleva a cabo Glas. Nos despedaza al despedazarse. ¿Qué nos hiere ahí? Cito a Derrida:

"nadie será capaz de probar que Glas pertenece, en su así llamada versión original, al elemento de la lengua francesa" 15

\footnotetext{
12 Butler, Judith: El grito de Antígona, Barcelona, El Roure, 2001.

13 Jameson, Fredric: Valences of the dialectic, Verso, 2009; pp. 102-112.

14 Derrida, Jacques: Glas, Paris, Galilée, 1974; p. 7 a.

15 Derrida, J. "Proverb: "He that would pun..." en Leavy, J.P. Glassary, University of Nebraska Press, Lincoln and London, 1986; p. 17 (la traducción es mía).
} 
Derrida escribe esto para que sea traducido y con la ocasión de una traducción, la traducción inglesa de Glas, editada en 1986. El problema de la recepción de un texto y de su repercusión no es separable del contexto lingüístico al que pertenezca ni del modo en el que se sitúe respecto a su llamada lengua materna. Glas, podría decirse, es un libro escrito en francés, pero quién sería capaz de afirmar que pertenece a la lengua francesa sólo por ello. ¿Y en qué afecta irreparablemente a la noción de pertenencia que pueda formularse semejante pregunta? ¿Qué es, entonces, pertenecer a la lengua francesa cuando un libro en francés puede serle ajeno? La pertenencia a la lengua, como cualquier pretensión de asignar una propiedad, es indecidible y cualquier determinación, siempre a posteriori, es resultado de una clasificación no exenta de violencia. Glas trabaja hasta el exceso el cuerpo no lingüístico de la escritura, la materialidad de la letra. Lleva el deseo de idioma y la singularidad idiomática al grado máximo de lo (in)traducible -que es la exigencia misma de la traducción-, a un punto en que las consideraciones ingenuas sobre el sentido o el significado se descalabran. Glas sólo puede decirse en francés, es más, ese sustantivo peculiar opera de tal modo en el libro que fuerza, en ocasiones, a considerarlo un nombre propio, a dejarlo sin traducir. Sin embargo, o tal vez debiéramos decir "por lo que", Glas no pudo ser asumido, la fidelidad al idioma inflige a éste una efracción que emborrona el sentido. Glas llega a convertir, trabajando desde lo idiomático, a la lengua en algo no reconocible. El deseo de idioma es un deseo imposible, se retuerce a sí mismo en el momento en que se pone en marcha.

Hasta el año 1986 no hubo ninguna traducción de Glas. El libro irrecibible en su lengua materna era, a la vez y por los mismos motivos, intraducible. Lo peculiar de Glas reside en su intraducibilidad interna y a la vez en su condición de radicalmente distinto de cualquier uso institucionalmente admitido de la lengua; de ahí, me atrevo a afirmar que en cierto modo Glas sólo puede recibirse desde fuera y como traducción casi imposible, incluso si se lo lee en francés. Flota entre las lenguas por la radicalidad con la que opera sobre la idiosincrasia del idioma hasta desfigurarlo. Glas resultaría, de hecho, un resto en la lengua, un bocado con el que se atraganta. De la figura del reciclaje pasamos a la de la absorción, Glas (de nuevo aglutinándose a sí mismo) sería un bocado que atraganta y que, además, se repite tras un largo proceso de digestión.

\section{Del libro y de los restos: guardar los restos para que se pierdan}

La digestión, proceso del espíritu, habría sido también uno de sus tópicos. Este libro de restos, o los restos de este libro, hace de la biodegradabilidad y la asimilación, en cierto modo, su tema; pero, a la vez, constriñe a ser leído desde ellos. Da las claves de su propia lectura produciendo peligrosamente un efecto cuasi-trans- 
cendental que parece confundirse con un saber absoluto, con el cierre perfecto de un bucle reflexivo del libro en el libro, con la presentación infinita del ya-ahí-deltodavía-no 16 como tiempo del libro. Hasta aquí, hemos dado por sentado, precipitadamente muchas cosas, por ejemplo, que hay tal cosa como un libro Glas. Efectivamente, así se vende en las tiendas, pero su materialidad altera los moldes usuales de presentación, pone en jaque a los intentos de editarlo. Rompe dentro del libro la forma-libro planteándonos una pregunta: ¿cómo han llegado esos textos a cerrarse en libro? Desde el inicio su disposición tipográfica sorprende: experimentación, gesto de vanguardia, sí; pero también ejercicio mimético del Libro de los libros, libro absoluto que contendría en él todos sus comentarios en un bucle infinito. Se ha sugerido que en su disposición en columnas Glas se asemejaría a la thorá. ¿Gesto de vanguardia o afirmación radical de una herencia imposible? No podemos zanjar en esa cuestión, pero podemos inventarnos una (pre)historia.

Es prudente desconfiar de las genealogías, también de las razones explanadas como narración; sin embargo, no me resisto a proseguir esta historia, elaborándola a partir de lo guardado en un archivo. El tiempo del archivo no es el tiempo de la historia, aunque se cuenten historias legitimadas con material de archivo. El archivo hace del tiempo geografía, va formando el terreno por una capa de sedimentos sólo narrables retrospectivamente para hacerlos verosímiles y dar credibilidad al narrador. El último esfuerzo por capitalizar los restos, ya que no por salvarlos, puede tomar la forma del archivo. Su posibilidad, guardar la huella, el acontecimiento como inscripción, abre la historia. Tomemos esto al pie de la letra.

Nunca sabremos como dos textos llegaron a encontrarse y tomar forma de libro, lo que podemos figurar es que Derrida utilizó los seminarios impartidos en los años anteriores a Glas como materiales para éste. La columna de Hegel responde, con algunas modificaciones, a los apuntes de "La famille de Hegel" y "Religion et philosophie". La columna de Genet también parece tener su germen en un seminario, impartido en París para los alumnos de la John Hopkins, intitulado "Le theátre de Genet". El Libro se elabora con los restos de diversos seminarios y recoge, a modo de anotación, sobre-inscripción, en judas o en el cuerpo principal (si hay tal cosa) del texto más pedazos de los cursos que Derrida impartía en aquellos años. Esto no tiene nada de sorprendente, cierto, y Derrida ha publicado como libro temas trabajados en sus cursos en otras ocasiones. Sin embargo el modo en el que ese material (ajustado a los cánones académicos) ha sido reescrito para producir uno de los libros de filosofía, quizá el libro, más inquietante e idiosincrático, en cuanto al trabajo sobre el soporte y el mecanismo de construcción, del siglo pasado, sí lo es. En primer lugar no hay ni rastro, ni resto, de un futuro encuentro entre Hegel y Genet en las notas de los seminarios. Segundo, las notas están tocado apenas, pero ese apenas produce un texto irreductible al texto del seminario con una operación mínima.

16 Cf. Derrida, Jacques : Glas, Paris, Galilée, 1974 ; p. 244. 
Cambia la acentuación, el texto se hace más elíptico y más abrupto; pero sobre todo cambia el espaciamiento, la disposición tipográfica. Hay otro trabajo sobre el papel (que quizá no se pueda llamar trabajo sino goce), se deja resonar de otro modo al soporte.

En esas dos columnas se han ido vertiendo y aglutinando diferentes tópicos, objeto de exposición por aquellos años. El libro es un inmenso vertedero en el que Hegel, el psicoanálisis, Kant, Marx, el origen del lenguaje y las bases pulsionales de la fonación, la mímesis y la physis, la filosofía, la retórica, la religión, la literatura etc. se extienden formando un tejido heterogéneo, una pasta llena de grumos que, sin embargo, funciona con un mecanismo de construcción casi perfecto. Las correspondencias entre columnas, elaboradas a posteriori, se suceden con un desfase cadencial de ritmo complejo, las repeticiones, sin saber si responden a un plan preconcebido o no, son en extremo productivas desde un punto de vista semántico y conceptual. Todo parece calculado al milímetro, y todo parece fruto del azar. La obra modernista, sólo comparada con Joyce, sólo comparable también, aparentemente irrecibible, pese a algunas buenas intenciones ${ }^{17}$, dentro de la institución universitaria ha salido de sus márgenes. Se ha elaborado con sus restos. La escritura de Glas, su llegar a hacerse libro, tiene algo ya de trabajo de duelo: trabajo encarnizado con los restos al que va a caerle encima, superponiéndose a los seminarios, y dando lugar a la operación glas, un reste y un déjà. Efectivamente, el reste y el déjà son añadidos posteriores, los más evidentes, los más remarcables y remarcados. El reste le ha caído encima y ha hecho -quizá -que se encuentren, es más, que se contagien un Hegel y un Genet. Ese resto que le cae al texto, curiosamente, parece describir al propio libro. Podemos anotar este efecto en el inicio truncado de Glas donde la palabra reste es, a la vez, nombre, verbo y partícula conectora. Antes de empezar el resto se disemina en una polivocidad que resiste e impulsa la traducción. Pero esas primeras páginas -insertadas en el cuerpo del seminario sobre la familia en Hegel y seguramente en el de Genet, en cuyas notas no se hacía referencia a su artículo sobre Rembrandt "Ce qui est resté..."18-ya se ha empezado, vienen de otro lugar, marcado por las minúsculas que inician el libro. El tiempo de la cita $-\mathrm{y}$ aún más cuando lo que se cita es "aquí y ahora" -es un tiempo coagulado, devuelto a la marca que abre su posibilidad de ser pensado19. Ese coágulo de tiempo disloca el

17 Cf. Ulmer, Gregory : Applied grammatology : Post(e)- Pedagogy from Jacques Derrida to Joseph Beauys, (Baltimore, Johns Hopkins University Press, 1985).

18 La primera frase de la columna izquierda de Glas está tomada del título, y a la vez primera frase, de ese artículo de Genet, publicado originalmente en Tel Quel en 1967. El texto estaba escrito también a dos columnas y que parece describirse en esos primeros párrafos del libro de Derrida: Genet, Jean "Ce qui est resté d'un Rembrandt déchiré en petits carrés bien reguliers et foutu aux chiottes" en Oeuvres complètes IV, (Paris, Gallimard, 1968).

19 Cf. Derrida, Jacques : “Ousia et grammé (note sur une note de Sein und Zeit)"en Marges de la philosophie (Paris, Minuit, 1972). 
presente y, por lo tanto, la historia como sucesión de presentes. Semejante resto sin origen se inscribe a lo largo del texto como "ya", "no deja ya de", déjà: adverbio que presenta una curiosa cercanía fónica al nombre invertido del firmante. El resto que disloca el texto es precisamente la instancia que asegura su continuidad y su legitimidad desde un supuesto fuera de texto. Derrida ya había analizado en otros lugares la relación entre el efecto transcendental y la muerte. Ese efecto transcendental como duelo se amplifica en el clamor. Las primeras páginas de Glas parecen describir al libro que se está escribiendo mientras nos describen el artículo de Genet; condensan el grueso de la operación de desplazamiento que se lleva a cabo sobre el corpus de Hegel y concentran por adelantado la propia historia del libro. El efecto es el de que Glas se lee a sí mismo, o mejor produce ese sí mismo al leer otros textos: reflexividad sin mácula que efectúa el libro absoluto en los restos del libro. Hay metalenguaje, la escritura como cita, referencia a lo siempre previo, a lo que nos lee por adelantado no puede evitar producir ese efecto cuasi-transcendental, pero como su "lenta agonía" 20 . Ese efecto se produce desde el otro, el otro que se lee en cada caso, y que de ese modo se incorpora, con el costo de la pérdida por la re-producción de los restos. El duelo triunfal es apenas un momento del trabajo de duelo. Si el duelo es un proceso de reescritura o reinscripción se entra ya en la economía indecidible del archivo, al escribir se producen residuos, que tratan de capitalizarse en la firma, en el "yo", residuos de residuos; pues siempre hay nuevos restos que gestionar cuando uno trata de ocuparse del resto. El clamor que anuncia el inicio del duelo dobla por un espectro, el muerto-vivo de la filosofía como institución desde sus bordes, duelo doblemente imposible. Glas ha elaborado el clamor de la universidad como custodia de la filosofía anticipándose a nuestro tiempo. De los restos del seminario, de los temas impuestos ha producido lo inesperado de un duelo que se adelanta y que se cuestiona a sí mismo desde el momento en que empieza por someter a interrogación la condición de restos de los restos, la premura de la herencia.

\section{La escritura como trabajo de duelo}

Glas habría, pues, elaborado su duelo, citando el duelo del otro. Esa re-citación del luto es un ejercicio de lectura y escritura que introyecta al texto, como resto. La lectura puede errar, pero no hay ninguna instancia que permita determinarlo a no ser su propia inscripción. Esa escritura-duelo construye criptas para lo que resta a través de un proceso contaminante que produce nuevos desechos y trabaja para su propia pérdida. El residuo produce la operación; pero, al no poder ser asimilado, mul-

${ }^{20}$ Cf. Derrida, Jacques: Glas (op. cit.) ; pp. 186-187bi. 
tiplica los restos. Siempre hay más de uno, siempre hay también más de un glas. El tañido fúnebre amplifica y repite su propio eco indefinidamente. Si el texto es el lugar de producción del resto por antonomasia, una vez que el concepto ha de inscribirse, incluso firmarse, ya no puede retornar a sí mismo. El concepto produce la fantasía de un duelo triunfante (no más que un momento para Freud) que lo reintegra todo sin pérdida, transformando la muerte en producción sin residuos. Pero ese trabajo de duelo pasa por un texto que ha tenido que ser firmado, dejando patente la vulnerabilidad indeleble de cualquier inscripción. Hegel intenta arreglárselas con sus propios fantasmas resistiendo, insistiendo sobre el cumplimiento del duelo. El Saber absoluto, el Sa en las siglas de Derrida, es la fantasía del duelo cumplido. Sin embargo, la introyección del resto y la subsiguiente producción de otros restos ensombrecen "la doncella plenitud del 1", sea esta recuperada. Siempre queda "una arruga, una sombra!"'21, un resto, pues, contaminando, desde un espacio que no se puede llamar interior, la victoria de la economía.

Repitamos: el monumento en el que Glas se reinscribe era ya un intento de restauración, quizá fallido, de una serie de restos. El glas (clamor) ya estaba, Derrida lo reitera y lo amplifica planteando las condiciones de lo heredable, sobre la sepultura que trata de salvar los restos en el monumento. El mausoleo era el trabajo de duelo como cumplimiento de la muerte. El $\mathrm{Sa}$, en efecto, era -ya -un glas. Para que haya duelo, para guardar los restos en un monumento hace falta un nombre propio. El clamor retorna del nombre propio. El nombre tiene que ver con lo muerto, ya en el texto de Hegel. La tarea de asignar nombres era el momento en el que se superaba la muerte del animal abriendo el elemento del espíritu. Éste sería ya un trabajo de duelo cuya primera tarea son los nombres 22 . Sin nombre ni cuerpo no hay duelo, es aquel el que abre su posibilidad, pero éste impone la exigencia del nombre.

El nombre propio, inscrito en el momento (aquí y ahora) en el que se firma, aglutina la irremediable dispersión de las citas, unificándolas como una instancia transcendental, pese a su muerte y por ella. Incluso en la ausencia, en la muerte del productor, el nombre debe seguir funcionando como garantía de propiedad. Sin embargo, el efecto transcendental está siempre amenazado, ya, desde la instancia de la firma. La iterabilidad, la legibilidad de la escritura provienen de su condición de marca que resta, que no se agota en el instante de su inscripción: resto de un aquí y ahora que es ya resto. La presencia es finalmente también, como muestra Hegel y Derrida remarca, (re)producción residual. Lo transcendental era ya clásicamente un duelo.

El clamor repite el intento de capitalizar la muerte con éxito, de dar al duelo la

21 "Y al encogerse de hombros los linderos/en un brusco desdén irreductible,/hay un riesgo de sierpes/ en la doncella plenitud del 1/¡Una arruga, una sombra!" del poema "Absoluta” de César Vallejo (Vallejo César: Los heraldos negros en César Vallejo: Obra poética, Madrid, CSIC, 1988; p. 80). 22 Cf. Hegel, G.W.F : Filosofia Real (México, F.C.E, 2006); p. 149-150 y 153 y ss. 
forma del trabajo. El libro-vertedero, salvación de los restos del saber en la institución para interrumpirla, es también el espacio superpoblado de un cementerio municipal. Monumento a los restos más que acumulación de residuos, aunque quizá el trabajo sobre el monumento del otro pueda tomar la forma de reciclaje. El resto, en su figura ejemplar de las basuras, puede ser de nuevo reinvertido como fundamento. Los restos pueden volver a reapropiarse, ni arrastrándolos más allá de la ontología se libra uno de hacer economía de ellos. En cierto modo todo libro es un resto: obra como resto que se pasa del sujeto, pero al cual el sujeto no pre-existe, pues no habría sujeto sin ese resto excremencial. Esa apenas figura resiste y toma la forma de una pregunta. ¿Por quién se toca a clamor? Por nadie, por nada, ninguna cosa; salvo quizá sí mismo. Pero... ¿Acaso hay algo así antes del tañido fúnebre que anuncia el duelo? Efectivamente -muchos lo han dicho ya -no. No hay tal cosa como un "sí mismo" sin la incorporación o introyección del "otro". El trabajo del duelo forma la frontera, luego es condición de que algo así como "yo" pueda enunciarse. El luto no se lleva sólo por el otro muerto, sino también por el otro, amado, vivo, por uno en el otro; y no termina -la cercanía entre duelo y melancolía en Freud lo apuntaba ya -del duelo siempre hay restos. El trabajo de incorporación pasa por lo in-corporable, por lo in-asimilable. Ese resto es la posibilidad de que algo se constituya como yo, inicio de cualquier operación reflexiva, trabajo de producción del yo y del otro, (re)producción de la interioridad. Es la experiencia instauradora de la frontera, y por ello la abisal de lo que suele nombrarse como política.

¿Trabaja, entonces, el clamor para producirse a sí mismo? ¿Para convertirse en el absoluto del libro en su constante juego meta-lingüístico? Recaemos de nuevo en esa pregunta. Derrida sospecha -así lo dice en Glas -de las puestas en abismo. Glas no asevera, tampoco -como otros lo hicieron - que no hay metalenguaje. Elabora su lenta agonía. Obra en un gesto doble su propio duelo en el del otro, pero quizá eso que acontece ahí ya no pueda pensarse como trabajo. Siguiendo a la tradición, Glas anuncia el duelo como trabajo. Lo que no deja indemne la noción general de trabajo, ni de producción que preside la economía aún vigente. El duelo fue pensado como trabajo de reubicación de la economía psíquica, pero ese trabajo se efectúa en torno a un resto nunca del todo asimilable y no produce otra obra que él. Así, en el momento en el que el duelo se convierte en el modelo de cualquier trabajo, revela, por un contra-movimiento, una estructura subyacente que la retórica de la producción oculta. La re-producción es siempre de los fantasmas, de la cosa misma. El fetiche le es intrínseco. La economía del resto pone en jaque a la economía. Si la economía moderna se elabora sobre una noción de trabajo como producción, circulación fantasmal del capital -que disfrazada de creatio ex nihilo esconde la acumulación, la extracción que la sostiene -en un presente pleno que intenta no mancharse con los restos de la reproducción del pasado que siempre está teniendo lugar como tal en cada momento de su ciclo, ha de considerar al residuo como 
un accesorio que no cuenta en las mediciones de la producción. Sin embargo, ese residuo le es esencial; por seguir en el discurso económico o en sus líneas de fuga, la producción capitalista (reproducción del capital) se alimenta de la acumulación por desposesión ${ }^{23}$, necesita a un otro del capitalismo que introyectar sin asimilarlo del todo, reverso del duelo. El residuo cuenta como lo esencial de la (re)producción, lo que se producen son residuos, puestos de nuevo en circulación a guisa de plusvalores. El supuesto exceso del plus esconde el minus de la adquisición como apropiación violenta. Una de las muchas formas que toma el resto en Glas es la del corte. La castración es un resto, pero el fetiche, reacción contra esta, también lo es. El suplemento no permite decidir si hay o no hay falta, la prótesis produce un exceso que cubre una falta que, de hecho, no hay (así el racimo de uvas de Stilitano extraído de una novela de Genet). Sarah Koffman, por ejemplo, remarcó que la disposición tipográfica de Glas era la escritura del fetiche ${ }^{24}$. Ese fetiche indecidible atraviesa, asimismo, los diferentes corpus, que más o menos despedazados, forman el tejido del libro. Un fetiche que pasa de texto en texto, de Kant a Hegel, a Freud, a Marx etc. quedando también como resto de la lengua, palabra extranjera levemente transformada. Como anota Derrida, comentando La razón en la historia de Hegel, fetiche viene de feitiço en portugués, la palabra es ya una herencia de la empresa colonial que abre la modernidad posibilitando la acumulación originaria.

Este discurso sobre el resto que yo trazo tras Glas es el resultado de un enfrentamiento con los grandes textos del pasado. El resto son restos, en primer lugar, restos en el texto con los que la lectura tropieza. De Hegel, Derrida se queda con las junturas del texto, los umbrales en los que el tránsito no termina de casar del todo, los pedazos mal asimilados, el afuera que trabaja el texto para su propia operación. Se queda con las figuras o las representaciones contingentes que, sin embargo, pueden tomar la forma del sistema que las integra, alterando la relación entre el todo y la parte más allá de la loa del fragmento. Si en el absoluto se trataban de salvar los restos del logos, aglutinando el discurrir histórico y sus fallas en un saber capaz de superar la historia condensándola, y de restaurar una eternidad que contuviese al tiempo, que el tiempo quede aún como un resto indeterminable en el texto que narra el saber absoluto constreñirá a releer a contrapelo todo el texto que trataba de contenerlo. El tono general de las páginas que lo tratan en Glas recuerda vagamente a Heidegger. Sin embargo, otra cosa está sucediendo desde el momento en que ya no sólo el $S a$ (saber absoluto) sino también el tiempo que aquel trataba de superar va a ser puesto entre comillas. El tiempo depende del esquema familiar (sólo hay tiempo en familia, de la familia25): el tiempo es también una categoría económica. El acontecimiento irrumpe como un resto de tiempo suspendido, el resto de la produc-

23 Cf. Harvey, David : El nuevo imperialismo (Madrid, Akal, 2003) ; pp. 116 y ss.

24 Koffman, Sarah :"Ça cloche" en Koffman, Sarah. Lectures de Derrida (Paris, Galilée, 1984).

25 Derrida, Jacques: Glas (op. cit.).; p. 248 y ss. 
ción del tiempo como historia y de su imposición en la geo-grafía, inscripción como producción de un tiempo y un espacio homogéneo. Queda como un resto el tiempo en el capítulo del $S a$, queda como resto (antes de empezar la empresa del Espíritu) el continente africano, espacio fuera de la historia como el "aquí y ahora" que precedía a la Fenomenología del Espíritu. Si África no llega a la historia es porque su religión se queda en el fetiche y su familia no llega a la mono-parental. Derrida muestra bien las incoherencias de la exposición hegeliana, la indecisión de su texto. Hegel había utilizado como fuentes para sus lecciones los libros publicados por geógrafos y exploradores de la época, asumiéndolos de un modo que hoy podríamos considerar acrítico. Había caído, por lo tanto, en lo que él mismo reprochaba al Kant de la Antropología desde un punto de vista pragmático, quedarse en lo meramente empírico. A Hegel le horrorizaba la definición kantiana de matrimonio, el doble perverso de lo transcendental revela en toda su crudeza los límites del "pornógrafo categórico"26. La geografía de la razón producía su propio resto en forma de saber popular, por ejemplo, vapuleado por todas las contingencias de la historia. Ni el tiempo como condición transcedental puede finalmente ser salvado; la experiencia se quiebra. Glas agranda esa brecha en la figura de un tiempo homogéneo. Si el libro puede leerse a sí mismo es que la temporalidad está rota, es que ya no podemos pensar la temporalidad como condición cuasi-transcedental, ni la historia como progreso, lo que presupone una homogeneidad temporal y espacial, un tiempo que sólo es pensable a partir de cierta determinación del espacio. Lo colonial y la historia se apoyan mutuamente. Los textos clásicos, citas de citas, espectros que desde la instancia del nombre asedian el texto, tropiezan en ese resto, residuos insalvables de la reproducción del espacio y el tiempo de la historia. El espacio colonial es el espacio de un cementerio en el que los mausoleos han dejado su lugar a las fosas comunes, por las que nadie pretende hacer duelo pero cuya negación produce restos que retornan como lo real en el espacio perforado de lo simbólico, la escritura.

Derrida encuentra ya restos, restos de restos, migajas que intentan ser salvadas en una operación violenta cuya plausibilidad será inmediatamente puesta en cuestión (ya en Marx el absoluto no encuentra sentido). De los restos de los restos Derrida hace su propio trabajo de duelo. De tantos duelos fallidos, un trabajo de duelo en el cuerpo de la lengua (siempre más de una, siempre del otro), en los restos también de lo biográfico, del yo que interrumpe la biografía y se disemina por el texto como una pequeña partícula que porta ya, no deja ya de hacerlo - repetición incesante -una temporalidad espectral. A la lengua sólo se llega por la escritura, y el goce de la escritura es el goce del papel, del cuerpo. Hay duelo, aún cuando ya no quede más espacio que el de un libro, roto de escritura, cuya ilegibilidad es nuestra responsabilidad, quizá más allá de la herencia.

26 Cf. Derrida, Jacques : Glas (op. cit.) ; pp. 146 y ss. 
El resto en Glas se coagula, en algunos puntos, en algunos momentos como déjà 27 , un pequeño adverbio que condensa una temporalidad espectral y el sonido iterado de un nombre propio. Diseminado por el texto el nombre pierde la propiedad, se pierde en una temporalidad previa al origen. Glas plantea por tanto otra biografía, la escritura del ni vivo ni muerto o el vivo-muerto. La biografía que asuma el duelo, y esto es, que se inscriba y reescriba las fronteras en las que el propio yo como resto del texto y del duelo se delimita. Esas fronteras abren el problema del texto no aún afuera o a un contexto, sino a otro resto geo-gráfico y geo-político. El seminario sobre Hegel empezaba con una nota referida a la piedra, otra piedra va a aparecer en el cuarto judas del libro, en la página 8 como una roca estéril entre África y Europa en el paso del mar al océano en un cruce que resulta una "especie de gollete de estrangulamiento histórico"28. De una frontera a otra: del borde al estrecho, el duelo nunca cumplido es el duelo de la producción del tiempo, del espacio, del cuerpo, el archivo de inscripción, el texto como condición de la historia. El trabajo del soporte se hace metonimia. La superficie de inscripción del archivo se releva frágil y porosa: "superficie fundante perforada" 29 .

Esa superficie fundante perforada es el que escribe, pero es más que eso. Podríamos llamarla con el nombre, entre Artaud y Derrida, de subjectil. El subjectil, como resto, es la superficie de inscripción y lo que escribe, el soporte perforado y el proyectil que lo perfora. Si recuerda vagamente a un cuerpo, sería a un cuerpo imposible previo a lo simbólico y a la diferenciación sexual: figura de un neutro no negativo. Su nombre, además, trae reminiscencias de la palabra sujeto. Sin embargo, éste no es un sujeto debilitado, hasta alcanzar la consistencia de una hoja, ni una matriz pre-subjetiva. Abre a un lugar que no es ni lo uno ni lo otro y que por ello puede convertirse en duelo (no lugar de duelo sino duelo como lugar) más allá del trabajo. Ese otro duelo ya no tiene más lugar que el goce del soporte, de la inscripción, de la lengua que resta. Si como decía Alvear, la literatura puede ser el intento de hacer el duelo por todos esos muertos sin sepultura, por esos muertos cuyo rechazo en lo simbólico hubo de tener -aunque se los excluya, invisibilice o no reconozca -efectos en lo real, el lugar de ese retorno es, en primer lugar, la lengua, tantas veces lengua del dominador (podríamos hacer la lista de los que escribieron en la

\footnotetext{
27 Véase: Derrida, Jacques. Glas (op. cit.); 26 b, 92 b, 97 bi, 152 b, 213 a y 291 b.

28 Op. cit; p. 7 aii

29 Tomo el término de Alvear, quien lo toma a su vez de la novela de Tununa Mercado Estado de memoria : "El enfrentamiento con la "superficie fundante perforada" ofrece el marco de un síntoma que había aparecido antes en el texto, cuando ella había sido sobrecogida por la imagen de "muertos que entraban por mis ojos y salían por mi nuca" (41). La misión restitutiva del texto de Mercado sería, entonces, ofrecer un entierro simbólico a esos muertos: la escritura sería la práctica en la que se vislumbraría una posible resolución de este peso traumático. Los muertos que no han sido enterrados, a los que se ha permitido quedarse alrededor". Avelar, Idelber Alegorías de la derrota: la ficción postdictatorial y el trabajo de duelo (Santiago, Cuarto propio, 2000); p. 187.
} 
lengua del otro Joyce, Kafka, Celan...y de los restos que reescribieron en ella). El libro -resto del goce de la inscripción en la lengua -se convierte en una metonimia del cementerio. Pero la inscripción no restituye voces, traza su desaparición. La herencia nos deja aún entre las leyes de la propiedad y la economía, en una escena familiar. La suspensión del duelo tampoco abre a la convivencia con los fantasmas...

Bolaño intentó en 2666 narrar lo inenarrable, en sus palabras:

"Estas ideas o estas sensaciones o estos desvaríos, por otra parte, tenían su lado satisfactorio. Convertía el dolor de los otros en memoria de uno. Convertía el dolor, que es largo y natural y que siempre vence, en memoria particular, que es humana y breve y que siempre se escabulle. Convertía un relato bárbaro de injusticias y abusos, un ulular incoherente sin principio ni fin, en una historia bien estructurada en donde siempre cabía la posibilidad de suicidarse.”30

La parte de las muertes tomó la forma de una novela policíaca, repetición asfixiante de los asesinatos, desaparición de cada una de las mujeres asesinada, de la que sólo nos quedaba (en el mejor de los casos) un nombre como resto. Las que un día estuvieron vivas y cuya muerte no pudo ser llorada aparecían marcadas dos veces por una nueva desaparición. No hay lugar para su voz en la novela; es el problema de cualquier historia. El duelo como trabajo inaugura la experiencia de la frontera, del yo, un duelo más allá de la producción y del trabajo, otro duelo, un duelo gozoso porque diga sí una y otra vez a su incumplimiento, porque quiera convivir con los espectros, quizá la subvierta. Nuestro intento de contar la historia de Glas ha fracasado seguramente. Él de nuevo nos anticipa, fuera de libro.

30 Bolaño, Roberto: 2666 (Barcelona, Anagrama, 2004); p. 244. 